\title{
A study on the influence factors of the university library service image based on SEM
}

\author{
Jinhua Xuan ${ }^{1,}$, , Mengqing Ding ${ }^{2, b}$ \\ ${ }^{1}$ The Library of Zhejiang University of Finance and Economics, China \\ ${ }^{2}$ Zhejiang University of Finance and Economics, China \\ apiaozhefan@126.com \\ dream5023056@126.com
}

Key words: University Library Service Image Elements SEM

\begin{abstract}
In this paper, we have discussed and analyzed the impact on the university library service image using questionnaire data of the college students in Zhejiang Area based on the Structural Equation Model (SEM). The determinants include the service time, the service consciousness, the service space and the service attitude. And not only that, but this study put forward tactics for the improve university library service image based on this paper's result.

Since 1996, China's Cultural Studies Library continues to heat up, many published articles, which greatly enriched the theoretical system of library science, provides a solid theoretical basis on the construction of the library culture and the development of the library. But as personnel training and scientific research base of university library, service should be regarded as its vocation and reflect scientific and social value with its unique diversity of literature books and the richness of data. But now, the image of university libraries in the service can not meet the demand to maintain a competitive advantage and sustainable development so far. Therefore, this paper will start from the basis of the service image of university library factors as the breakthrough point, according to the sample of 200 investigation data of Zhejiang Higher Education Park, 7 colleges and universities to empirical research the elements which will influence the impact of the university service image through structural equation model in the points of perspective of service consciousness, service hours, service space and service attitude.
\end{abstract}

\section{The influence factors of library service image}

Anne F. Roberts et al.,(1989) considered that the library service image is the sum of unique values, behavior, management style, library spirit, ethics which gradually develop under the certain social and historical context during the long term management of activities to service for readers. It is subject to common underlying ideology of material culture, behavior, institutional culture and all librarians . Qin Qiwen(2004) believes that the image of university library services should be defined by three dimensions from the relationship of subject, object to subject and object. Subject, service image of university library is the library staff of the service intension and service attitude. Object, service image of university libraries is the overall appraisal and impression of the university teachers and students to staff service intension and service attitude.

On the basis of the literature, there are four component elements of the service image of university library: service time, service space, service intension and the service attitude. The service time refers to the time when the library provides service. The service space refers to material carrier of university library building, facilities, equipments, books, furnishings and other services. The service consciousness refers to the staffs' enthusiasm and intension as well as their mental preparation to do better work. The service attitude refers to the staffs' attitude and behavior performance during the process for serving. 


\section{An empirical analysis of factors affecting the service image library based on SEM}

2.1 Structural equation modeling (SEM) analysis process. Structural equation model integrates path analysis, confirmatory factor analysis test and general statistical method, which can analyze the causal relationship between variables, including the advantages of factor analysis and path analysis. At the same time, it remedies the defect of factor analysis without being restricted by the assumptions of path analysis because of the consideration of the error factors.

Generally speaking, structural equation model consists of three equations:

$$
\begin{aligned}
& \eta=B \eta+\Gamma \xi+\zeta . \\
& y=\Lambda_{y} \eta+\varepsilon . \\
& x=\Lambda_{x} \xi+\sigma .
\end{aligned}
$$

The structural equation model above consists of the measurement model and structural model. Equation (2-1) is a structural model, (2-2) and (2-3) is a measurement model. Structural model explains the causal relationship between potential exogenous variables and latent endogenous variables, which is expressed in graphical form called road map. $\Gamma$ is structure coefficient matrix, $\xi$ is potential exogenous variable matrix, $\eta$ is latent endogenous variable matrix, $B$ is the coefficient of structural models in $\eta, \xi$ is residual value. The measurement model illustrates the relationship between potential $\eta$, $\xi$ and measurement of variables y and $x$. In the equation (2-2), y is a matrix measured variables of $\eta ; \Lambda_{y}$, the measurement of coefficient matrix, expresses the relationship between potential endogenous variable matrix $\eta$ and its measurement variable $y ; \eta$ is latent endogenous variable matrix; $\varepsilon$ is a matrix of measurement equation residuals. In the equation (2-3), $\mathrm{x}$ is a matrix of measured variables of $\zeta ; \Lambda_{\mathrm{x}}$ is measurement of coefficient matrix, which expresses the relationship between potential exogenous variable matrix $\xi$ and its measurement variable $\mathrm{x}, \xi$ is potential exogenous variable matrix; $\sigma$ is a matrix of measurement equation residuals. The Data processing software used in this paper is AMOS7.

2.2 Data selection and variable definitions.In order to understand the factors influencing service image of our library, questionnaire surveys outline are designed from the points in service attitude, service spaces, service time and service intension, and more than 200 college students from seven universities in Zhejiang Higher Education Park(Zhejiang Gongshang University, Zhejiang University of Finance and Economics, Hangzhou Normal University, Zhejiang Sci-Tech University, Hangzhou Dianzi University, China Jiliang University) participated in this survey and exchange

\begin{tabular}{|c|c|c|c|c|c|c|c|c|c|}
\hline & $\begin{array}{l}\mathrm{N} \\
\mathrm{o} .\end{array}$ & questions & & Very satisfied & Satisfied & General & Poor & Very Poor & Total \\
\hline \multirow{6}{*}{$\begin{array}{l}\text { Service } \\
\text { attitude }\end{array}$} & \multirow{2}{*}{$\begin{array}{l}\mathrm{a} \\
1\end{array}$} & \multirow{2}{*}{$\begin{array}{l}\text { Friendly and } \\
\text { helpful staff }\end{array}$} & copies & 40 & 60 & 47 & 40 & 13 & 200 \\
\hline & & & $\%$ & 20 & 30 & 23.5 & 20 & 6.5 & 100 \\
\hline & \multirow{2}{*}{$\begin{array}{l}\mathrm{a} \\
2\end{array}$} & \multirow{2}{*}{$\begin{array}{c}\text { Staff have the } \\
\text { patience }\end{array}$} & copies & 40 & 40 & 64 & 44 & 12 & 200 \\
\hline & & & $\%$ & 20 & 20 & 32 & 22 & 6 & 100 \\
\hline & \multirow{2}{*}{$\begin{array}{l}\mathrm{a} \\
3\end{array}$} & \multirow{2}{*}{$\begin{array}{l}\text { Understand the } \\
\text { reader needs }\end{array}$} & copies & 80 & 26 & 48 & 34 & 12 & 200 \\
\hline & & & $\%$ & 40 & 13 & 24 & 17 & 6 & 100 \\
\hline \multirow{6}{*}{$\begin{array}{l}\text { Service } \\
\text { time }\end{array}$} & \multirow{2}{*}{$\begin{array}{l}\mathrm{a} \\
4\end{array}$} & \multirow{2}{*}{$\begin{array}{c}\text { Provide } \\
\text { real-time } \\
\text { service } \\
\end{array}$} & copies & 34 & 41 & 53 & 38 & 34 & 200 \\
\hline & & & $\%$ & 17 & 20.5 & 26.5 & 19 & 17 & 100 \\
\hline & \multirow{2}{*}{$\begin{array}{l}\mathrm{a} \\
5\end{array}$} & \multirow{2}{*}{$\begin{array}{l}\text { the satisfaction } \\
\text { of the open time }\end{array}$} & copies & 44 & 33 & 46 & 61 & 16 & 200 \\
\hline & & & $\%$ & 22 & 16.5 & 23 & 30.5 & 8 & 100 \\
\hline & \multirow{2}{*}{$\begin{array}{l}\mathrm{a} \\
6\end{array}$} & \multirow{2}{*}{$\begin{array}{l}\text { Opening hours } \\
\text { during the } \\
\text { holidays }\end{array}$} & copies & 33 & 64 & 59 & 31 & 13 & 200 \\
\hline & & & $\%$ & 16.5 & 32 & 29.5 & 15.5 & 6.5 & 100 \\
\hline \multirow{3}{*}{$\begin{array}{l}\text { Service } \\
\text { space }\end{array}$} & \multirow{2}{*}{$\begin{array}{l}a \\
7\end{array}$} & \multirow{2}{*}{$\begin{array}{c}\text { beautiful library } \\
\text { construction }\end{array}$} & copies & 72 & 71 & 31 & 19 & 7 & 200 \\
\hline & & & $\%$ & 36 & 35.5 & 15.5 & 9.5 & 3.5 & 100 \\
\hline & $\mathrm{a}$ & Orderly & copies & 59 & 68 & 47 & 13 & 13 & 200 \\
\hline
\end{tabular}
with iedas. Summary information is shown in Table 1.

Table 1 Frequency survey data analysis table 


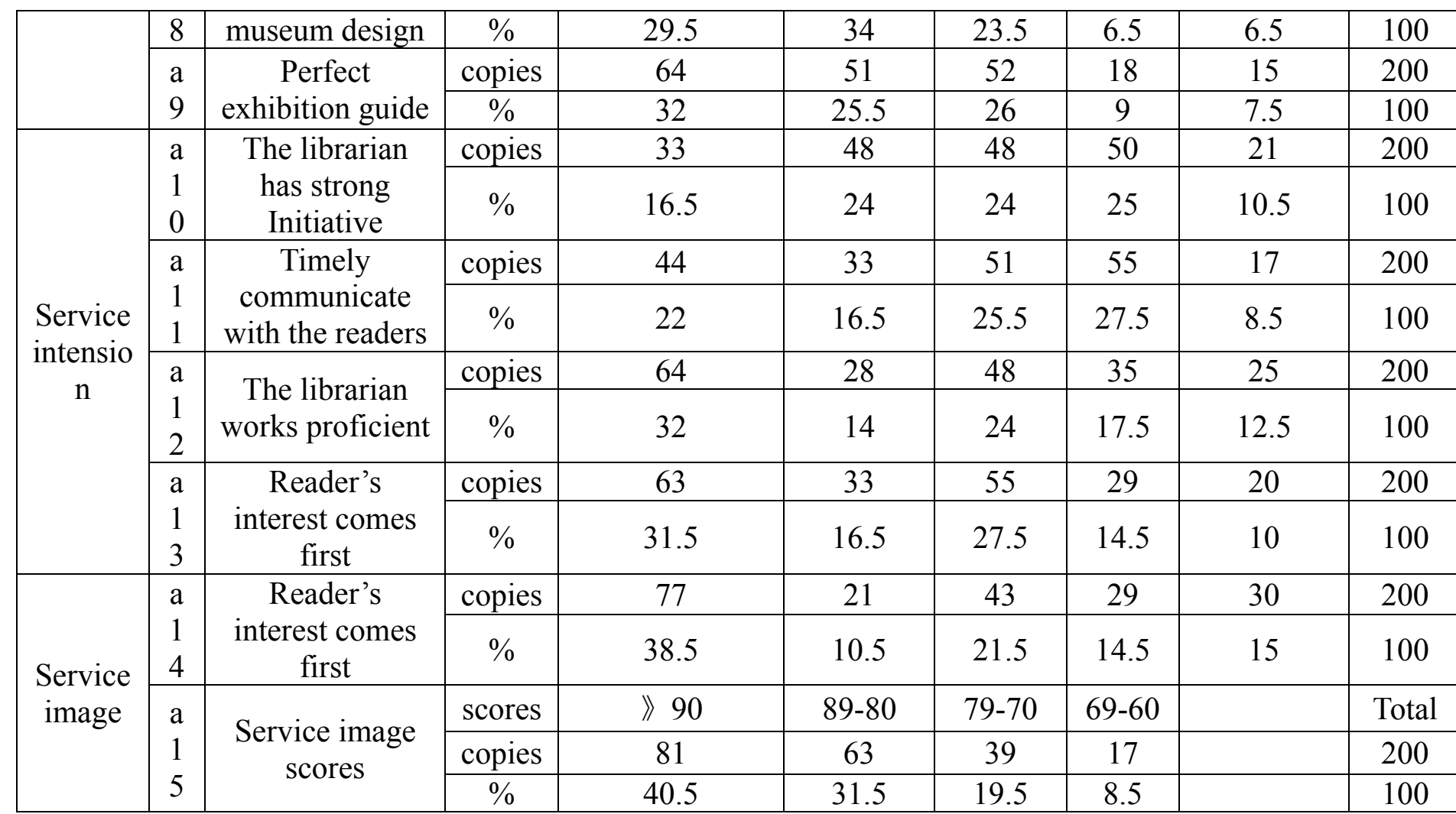

Table 1 shows that the highest satisfaction is the service space, to which satisfaction reached $65 \%$, but as a service provider, librarians in the university library service innovation plays a vital role. Library service quality, service level and depth is the key to improving the image of library services. The four aspects of service meant the title, satisfaction is very low $(40.5 \%, 38.5 \%, 46 \%$ and $48 \%)$.

2.3 Estimation of model fitting degree and path coefficient.Reliability in the structural equation model refers to the consistency and stability of the measurement results, that is, to keep the error of the measurement results in a smaller range, observed values will not change along with the change of form or time. From the table 2, Cronbach 's was 0.585 , more than the critical value of 0.35 , fitness value (GFI, AGFI, NFI and CFI) is close to 1, indicates that the simulation results are satisfactory, the model can be accepted. The amendment process through residual value and the error value, model output path was eventually accepted as shown in figure 1.

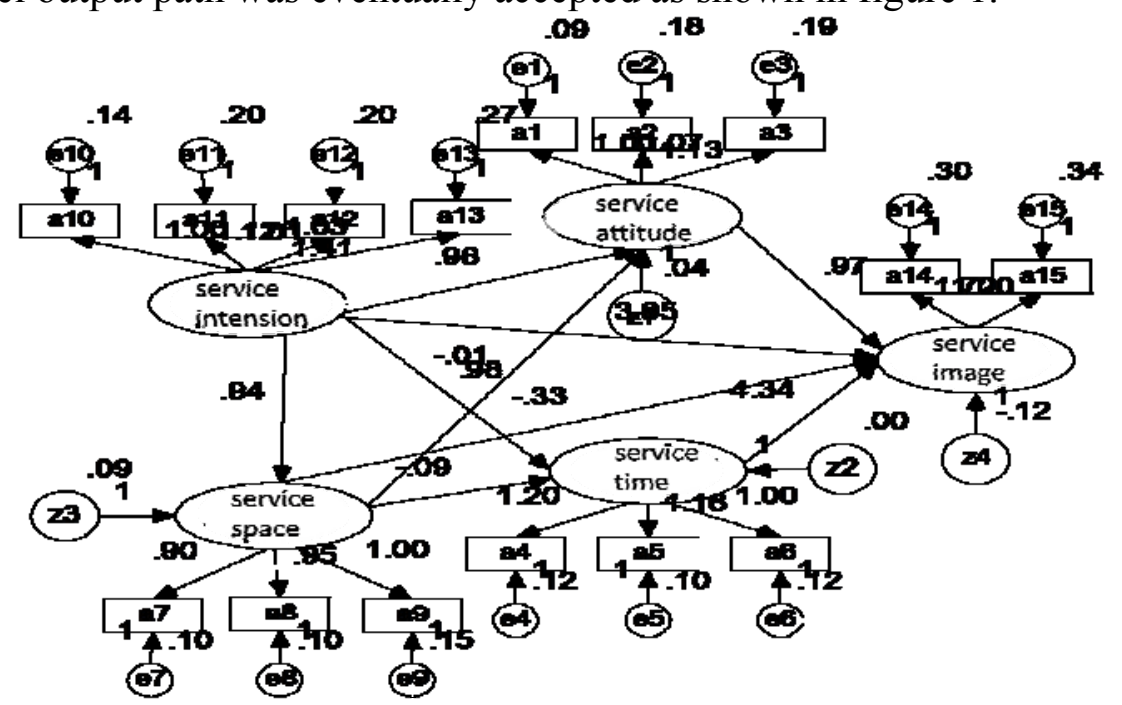

Fig. 1. The library image structure path graph

Table 2 Cronbach's a and adaptation value

\begin{tabular}{|c|c|c|c|c|c|c|}
\hline Index & Cronbach's Alpha & GFI & AGFI & RMSEA & NFI & CFI \\
\hline & 2.861 & 0.924 & 0.902 & 0.079 & 0.908 & 0.921 \\
\hline
\end{tabular}

The estimation and test results of the path coefficient from table 3, "service intension" to "service 
space", " service time " and "service attitude", the path coefficient of " service attitude" to "service image" has reached a significant level of 0.01 . The path coefficient of "service attitude" on a2 and a3, " service time " on a4, a5 and a6, " service space " on a7, a8 and a9, " service intension " on a11, a12 and a13, "service image" of a14 and a15 were all significant at 0.01 level.

Table 3 Estimation of path coefficient

\begin{tabular}{|c|c|c|c|c|c|c|}
\hline & & & $\begin{array}{r}\text { Estimat } \\
\mathrm{e}\end{array}$ & S.E. & C.R. & $\mathrm{P}$ \\
\hline Service space & $<---$ & $\begin{array}{l}\text { Service } \\
\text { intension }\end{array}$ & 0.945 & 0.036 & 26.205 & *** \\
\hline Service time & $<---$ & $\begin{array}{l}\text { Service } \\
\text { intension }\end{array}$ & 0.984 & 0.096 & 10.248 & $* * *$ \\
\hline Service time & $<---$ & Service space & -0.092 & 0.095 & -0.969 & 0.333 \\
\hline Service attitude & $<---$ & Service space & -0.008 & 0.109 & -0.074 & 0.941 \\
\hline Service attitude & $<---$ & $\begin{array}{l}\text { Service } \\
\text { intension }\end{array}$ & 0.965 & 0.109 & 8.888 & $* * *$ \\
\hline Service image & $<---$ & $\begin{array}{l}\text { Service } \\
\text { intension }\end{array}$ & 3.947 & 7.129 & 0.554 & 0.58 \\
\hline Service image & $<---$ & $\begin{array}{l}\text { Service } \\
\text { attitude }\end{array}$ & 0.975 & 0.202 & 4.815 & $* * *$ \\
\hline Service image & $<---$ & Service time & -4.339 & 7.034 & -0.617 & 0.537 \\
\hline Service image & $<---$ & Service space & -0.328 & 0.881 & -0.372 & 0.71 \\
\hline $\mathrm{a} 2$ & $<---$ & $\begin{array}{l}\text { Service } \\
\text { attitude }\end{array}$ & 1.129 & 0.034 & 33.49 & $* * *$ \\
\hline a5 & $<---$ & Service time & 1.162 & 0.034 & 34.058 & *** \\
\hline a8 & $<---$ & Service space & 0.946 & 0.03 & 31.53 & $* * *$ \\
\hline a11 & $<---$ & $\begin{array}{l}\text { Service } \\
\text { intension }\end{array}$ & 1.008 & 0.035 & 28.761 & $* * *$ \\
\hline a10 & $<---$ & $\begin{array}{l}\text { Service } \\
\text { intension }\end{array}$ & 1 & & & \\
\hline a12 & $<---$ & $\begin{array}{l}\text { Service } \\
\text { intension }\end{array}$ & 1.117 & 0.037 & 30.162 & *** \\
\hline a13 & $<---$ & $\begin{array}{l}\text { Service } \\
\text { intension }\end{array}$ & 1.03 & 0.039 & 26.546 & $* * *$ \\
\hline a1 & $<---$ & $\begin{array}{l}\text { Service } \\
\text { attitude }\end{array}$ & 1 & & & \\
\hline a3 & $<---$ & $\begin{array}{l}\text { Service } \\
\text { attitude }\end{array}$ & 1.075 & 0.033 & 32.21 & $* * *$ \\
\hline a14 & $<---$ & Service image & 1 & & & \\
\hline a15 & $<---$ & Service image & 1.716 & 0.097 & 17.744 & *** \\
\hline a7 & $<---$ & Service space & 0.903 & 0.029 & 30.682 & *** \\
\hline a9 & $<---$ & Service space & $\frac{1}{1}$ & & & \\
\hline $\begin{array}{l}\mathrm{a} 4 \\
\mathrm{a} 6\end{array}$ & $\begin{array}{l}<--- \\
<---\end{array}$ & $\begin{array}{l}\text { Service time } \\
\text { Service time }\end{array}$ & $\begin{array}{r}1.196 \\
1\end{array}$ & 0.035 & 33.708 & w* \\
\hline
\end{tabular}

2.4 The empirical results. Through the consolidation of table 4, we can conclude that the total effect degree on the independent latent variable to the dependent latent variable. From table 4 we can draw the following conclusions:

Table 4 The comprehensive effect coefficient table

\begin{tabular}{|c|c|c|c|c|c|}
\hline & $\begin{array}{c}\text { Service } \\
\text { intension }\end{array}$ & $\begin{array}{c}\text { Service } \\
\text { space }\end{array}$ & $\begin{array}{c}\text { Service } \\
\text { time }\end{array}$ & $\begin{array}{c}\text { Service } \\
\text { attitude }\end{array}$ & Service image \\
\hline Service space & 0.945 & 0 & 0 & 0 & 0 \\
\hline Service time & 0.898 & -0.092 & 0 & 0 & 0 \\
\hline Service attitude & 0.957 & -0.008 & 0 & 0 & 0 \\
\hline Service image & 0.674 & 0.062 & -4.339 & 0.975 & 0 \\
\hline
\end{tabular}

(1) Library service intension has positive influence of the service space, service time, service attitude and service image, and the coefficients is $0.945,0.898,0.957$ and 0.674 , which shows the sense of service is the key to improving the services image of library.

(2)Service space has a negative impact on service time and service attitude, the coefficient is -0.092 and -0.008 , demonstrating that the service time setting should respect the needs of readers and improving service attitude. 
(3)The impact coefficients of service spaces and service attitude to service image is 0.062 and 0.975 respectively, the service time on the service image coefficient is -4.339 , indicating that optimize university library service hours,make readers greatest satisfaction is one of the vital strategies to improve the services image of the library.

\section{Conclusion}

From empirical study in 200 investigation data of 7 colleges and universities in Zhejiang Higher Education Park, we can conclude that the main factors leading to the service image is relatively low in the sense of service, service attitude and sevice time satisfaction. Thus, measures need to be taken to further enhance its service image.

First of all, strengthen the sense of service and innovate the service concept. In 21th Century, we ushered in the era of knowledge economy, the library staff must further clear objectives and guide ideology of library construction, strengthen the service consciousness, improve their own quality, do a good job in the new century library work.

Second, improve service attitude, specify service behavior. Librarians who communicate with readers every day, should provide them with books of intelligence information, then readers could search for what they need. So the librarians and readers should have good communication on information, ideas and emotion, reaching a goal to achieve mutual understanding, resolve conflicts friendship and cooperation, then the potential value of library materials could be further utilized.

Third, optimize service time and improve service efficiency.There are two aspects to optimize the library sevice time, One is the specific requirements on the service of University Library from the laws and regulations, and further improve the service standard of time to adapt the library services and education reform; The second one is the university library itself should further correct the library-running idea, strengthen the service consciousness and carefully study the law of demand of readers, to improve the level of management, the establishment of self-study room (extend the opening hours), maximum satisfy the needs of readers.

\section{References}

[1]Anne F. Roberts and Susan Grigwold Blandy. Public Relations for Librarians[M].Englewood CoLo: Libraries Unlimited Inc,pp, 11-23,1989.

[2]Qiwen Qin and Yongkang Zhou, Image introduction, Social Sciences Academic Press, pp. 8-10, 2004.

[3]Gaofeng Li,Cultural Construction of Library, The Library Journal of Henan ,pp, $42-44,2006$.

[4] Cook c, Heath F. SERVQUAL and the quest for new measures, Journal of Library Administration, pp,37-40,2002.

[5] Lei Liu, Yinghua Feng and Yi Jiang, The needs research of college students about Library 2.0 personalized information service-Taking Nanjing universities for example, Library Forum, pp.27-33, 2011.

[6]Mleilin Huang, Analysis of the university library of users' participation behavior, Library Forum, pp.24-27, 2012.

[7]Bollen, K. A., and R. A. Stine, Bootstrapping goodness-of-fit measures in structural equation models,Sociological Methods and Research,pp, 205-229,2001.

[8]Taisheng Rong, AMOS and research methods, Chongqing University press,pp,92-134,2009.

\section{Acknowledgment}

Project of Zhejiang Education Office 《Study on the mechanism and influence factors of the formation of Zhejiang university library cultural value(Y201119992)》 